\title{
Epidemiología y factores de riesgo asociados al botulismo de los alimentos y al botulismo infantil: ¿Dónde y cuándo?
}

\author{
Mariela Tornese, M. Laura Rossi, Florencia Coca, Cecilia Cricelli y Alcides Troncoso
}

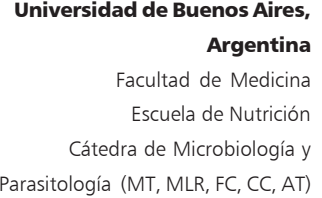

Recibido: 10 de julio de 2007 Aceptado: 1 de octubre de 2007

Correspondencia a: Alcides Troncoso microbiologiayparasitologia@yahoo.com.ar

\section{Epidemiology and risk factors associated to foodborne and infant botulism: Where and when?}

Foodborne botulism is caused by ingestion of a preformed toxin produced in food by C. botulinum. The most frequent source is home-canned foods, in which spores that survive an inadequate cooking and canning process germinate, reproduce, and produce this toxin in the anaerobic environment of the canned food. From 1992 to 2003, 34 cases of food-borne cases and 275 cases of infant botulism were reported in Argentina. The severity of symptoms depends on the amount of toxin ingested. Mild cases may not seek medical attention at all. A patient presenting only nausea and mild neurological symptoms may not raise the physician's attention and therefore the case will not be reported. It is important to make physicians aware of this potentially fatal disease. In Argentina, most botulism cases are related to home-canned food. Therefore, botulism can be prevented through the education of consumers in order to discourage the consumption of that kind of food.

Key words: botulism-Clostridium botulinum-infant botulism.

Palabras clave: botulismo-Clostridium botulinum-botulismo infantil.

\section{Introducción}

$\mathrm{E}$ l botulismo es una enfermedad paralizante debida a neurotoxinas secretadas por una bacteria anaeróbica, formadora de esporas: Clostridium botulinum. Existen siete toxinas inmunológicamente distintas, designadas con las letras A hasta la G. Los tipos A, B, E y F provocan la mayoría de los casos en el hombre. Las neurotoxinas de C. botulinum bloquean, en la presinapsis, las placas neuro-musculares colinérgicas autónomas, lo que impide la estimulación de las fibras motoras ${ }^{1}$.

La enfermedad clínica se caracteriza por parálisis de los nervios craneales, seguida de parálisis muscular fláccida descendente y puede involucrar a los músculos de la respiración, más específicamente, la musculatura laríngea, con disminución de la secreción salival y sequedad de la mucosa bucal. A pesar de que la ptosis y la disartria pueden confundirse con signos de encefalopatía, los pacientes están totalmente conscientes y afebriles. El período de incubación, luego de ingerida la toxina, es de 12 a 36 horas. Con frecuencia, los síntomas neurológicos están precedidos por náuseas, vómitos, dolor abdominal y diarrea. La recuperación, generalmente, lleva de semanas a meses, dependiendo de la gravedad. Los pilares principales de la terapia son el apoyo meticuloso de unidades de cuidados intensivos, con ventilación mecánica en los casos más graves y la administración de antitoxina equina trivalente. Esta antitoxina, administrada a tiempo, puede detener la progresión de la parálisis y reducir la duración de la enfermedad ${ }^{2}$.

El botulismo es causado por la ingesta de alimentos que contienen la neurotoxina preformada de C. botulinum, cuyas esporas están omnipresentes en el medio ambiente. El adecuado proceso de la conservación de alimentos requiere de la eliminación o limitación de los factores necesarios para que los microorganismos patógenos puedan crecer y del correcto enfriamiento y almacenamiento para limitar la recontaminación. Para poder crecer y producir toxinas, C. botulinum requiere una atmósfera anaeróbica, nutrientes, temperatura apropiada, disponibilidad suficiente de agua, un ambiente con la acidez necesaria y libre de inhibidores del crecimiento.

Se puede controlar el crecimiento de C. botulinum en productos alimenticios a través del control de la acidez $(\mathrm{pH})$ y de la actividad de agua $\left(\mathrm{A}_{\mathrm{w}}\right)$, refrigeración y conservantes químicos. Para que un alimento sea seguro, su conservación debe realizarse en un medio ácido (pH de 4,6 o menor); a estos niveles se inhibe la producción de la letal toxina del botulismo. 
alimentación de los diversos países. Es importante saber que cualquier alimento que permita la multiplicación del microorganismo y la generación de su toxina, cuyo procesamiento inadecuado permita la supervivencia de la espora, o bien, que no sea calentado antes de su consumo, conlleva potencial riesgo de la ocurrencia de brotes de enfermedades transmitidas por alimento (ETA).

En el período comprendido entre los años 1990 y 2000, 160 brotes de botulismo de los alimentos han afectado a 263 personas en E.U.A. Veintiséis por ciento de las personas requirieron asistencia respiratoria mecánica y la tasa total de letalidad fue de 5\%. Los alimentos implicados en $50 \%$ de los brotes, eran comidas envasadas en forma casera: sopas, salsa de tomate, ajo en aceite, guiso, ensalada de papas, salchichas caseras, y menos frecuentemente, albóndigas, bife, paté de hígado, budín de pan, salsa de pastel de manzana, hamburguesa, chili y peyote ${ }^{4}$.

Los brotes asociados a restaurantes fueron bien documentados en E.U.A. y han causado un desproporcionado número de casos. Varios brotes han sido producidos por alimentos preparados en restaurantes, entre ellos salsa skordalia, elaborada en base a papas y una salsa de queso envasada. El primer brote ocurrió en Texas en 1993, afectando a 17 personas. Esta salsa había sido preparada con papas que fueron cocinadas en papel aluminio y permanecieron envueltas en el mismo, a temperatura ambiente, por varios días. La investigación epidemiológica de este brote identificó la práctica de dejar la papa hervida envuelta en papel aluminio a temperatura ambiente como el principal peligro; esta práctica debe ser eliminada de los restaurantes y hogares. Las medidas de control dependen de la educación y concienciación de quienes trabajan en restaurantes y de los esfuerzos de las autoridades sanitarias $^{3}$.

Otro brote por salsa skordalia ocurrió en Georgia en 1993, afectando a ocho personas. Se relacionó con salsa de queso envasada e ingerida luego de que dicho envase fuera dejado en el restaurante sin refrigeración ${ }^{4}$. Las malas prácticas de manipulación de los alimentos que favorecen la germinación y crecimiento de C. botulinum y el desarrollo subsiguiente de su toxina, han sido identificadas al envolver en ambiente de anaerobiosis las comidas caseras ${ }^{4}$.

El botulismo asociado a las recetas tradicionales con pescados sin eviscerar, es bien documentado en preparaciones como el fasikh egipcio y el kapchunka de Europa oriental. El brote de botulismo E de 1992 por mohola, un pescado tradicional egipcio curado con sal, comprado en un mercado de New Jersey, se encuentra dentro de esta categoría y fue el primer brote comunicado que se asoció a peces comercializados,
Los tipos de alimentos involucrados en casos y brotes varían según los hábitos de conservación y de 
pero incorrectamente manipulados. En Hawai, en 1990, se produjeron tres casos de botulismo tipo B causados por un tipo de pescado palani. Este brote fue novedoso porque el pescado fue comprado fresco en un establecimiento minorista, pero cocido insuficientemente. La enfermedad grave pareció ser asociada con la ingesta de los intestinos de pescado poco coci$\operatorname{dos}^{5}$. Desde entonces, en muchos lugares se prohibe la venta de pescado sin eviscerar*.

Un brote de botulismo tipo B, que afectó a una persona en Oregon en 1997, fue causado por un burrito (preparado regional del norte de México que consiste en una tortilla grande de trigo que envuelve diversos tipos de relleno, como legumbres, carne, queso o la combinación de éstos), adquirido en un puesto de venta callejera. Otro brote de botulismo tipo A que afectó a una persona en California en 1994, fue atribuido a una salsa de porotos que había sido guardada en un contenedor plástico a temperatura ambiente; la instrucción “Conservar refrigerada” estaba impresa en letra minúscula en el envase.

Un brote de botulismo tipo A, que afectó a dos personas en California en 1994, fue causado por un paquete de sopa de almeja producido comercialmente. La sopa era un producto bajo en ácidos y había sido colocada en una bolsa de plástico sellada. A pesar de que el producto era perecedero y se vendía en un refrigerador en una verdulería, llevaba una etiqueta de "No perecedero" con instrucciones de refrigerar. El paciente guardó la sopa a temperatura ambiente durante varias semanas y luego la ingirió a pesar del mal olor y sabor ${ }^{4}$.

Desde 1990 hasta el año 2000, un total de 91 casos de botulismo ocurrieron en Alaska. Exploradores árticos y balleneros han descrito la muerte de familias enteras de nativos que consumieron carne de ballena ${ }^{6}$. La tasa de mortalidad por botulismo en nativos ha caído en las décadas recientes ${ }^{7}$. Antes de 1961, la tasa de mortalidad era de aproximadamente 50\%; de 1967 a 1974 se redujo a 9\% ${ }^{8}$. Desde 1990 al 2000, esta tasa promedió el 3\%, siendo la tasa más baja de los otros 50 estados americanos. Pero si bien la tasa de mortalidad por botulismo entre los nativos de Alaska ha declinado en los últimos 20 años, la incidencia de la enfermedad ha aumentado.

De hecho, la incidencia del botulismo en este país está entre las más altas del mundo y todos los casos han sido asociados con la ingesta de los tradicionales alimentos nativos artesanales, incluidos mamíferos acuáticos fermentados, como muktuk (piel y grasa rosada ubicada inmediatamente debajo de la piel de la ballena), cola de castor, aleta y aceite de foca. Otros fueron causados por pescados como cabeza de salmón fermentada y pescado blanco; o huevos de pescado fermentados. El $88 \%$ de los casos fue causado por toxina tipo E. De los siete tipos de toxinas botulínicas, la toxina tipo E está exclusivamente asociada con la ingesta de animales acuáticos ${ }^{9}$.

A modo ilustrativo, McLaughlin J y cols, describieron un brote de botulismo tipo E asociado a la ingesta de ballenas varadas. El 12 de julio de 2002, dos residentes de la aldea Yupik, en el oeste de Alaska, encontraron un esqueleto de una ballena varada en el litoral del Mar de Bering, que parecía haber muerto en ocasión de esa primavera. Ellos recolectaron la cola para consumo, la cortaron en trozos, y los colocaron en bolsas plásticas sellables. Las porciones fueron refrigeradas y distribuidas a familiares y amigos. Entre el 13 y el 15 de julio, un total de 14 esquimales comieron del muktuk crudo. De las 14 personas identificadas que lo consumieron, ocho (57\%) tenían la enfermedad y todas las muestras del alimento analizadas fueron positivas para el tipo E de toxina botulínica ${ }^{10}$.

\section{Botulismo en Argentina}

El botulismo es un importante problema de salud pública en Argentina, conocido desde 1922, cuando el primer brote, causado por espárragos en conserva casera, fue reportado en Mendoza ${ }^{11}$. Los brotes de botulismo en nuestro país han sido causados, principalmente, por comer vegetales y carnes incorrectamente envasadas y conservadas en forma casera. Los alimentos implicados en los brotes incluyeron jamón, pimientos rojos y verdes, vizcacha, berenjena, cohombros, corazones de la palma, tomates, duraznos, espinaca y un tipo de queso con cebollas ${ }^{12}$. Uno de los brotes ocurrió en enero de 1998 en Buenos Aires y afectó a varios choferes de colectivos. De once personas que consumieron el alimento, nueve (82\%) desarrollaron la enfermedad. La neurotoxina tipo A fue detectada y el alimento asociado al brote fue el matambre (carne arrollada y rellena). Dicho alimento había sido cocido en agua a una temperatura de 78 a $80^{\circ}$ C durante cuatro horas, envasado, sellado en una bolsa de plástico y refrigerado inadecuadamente, lo que contribuyó a que $C$. botulinum pudiera sobrevivir, germinar y sintetizar las neurotoxinas causantes de la enfermedad ${ }^{13}$.

\footnotetext{
* Nota del Editor: En Chile está proscrita la venta de pescado con vísceras. Decreto Supremo 977 de 1996. Reglamento Sanitario de los Alimentos, Artículo 317.
} 


\section{Botulismo infantil en Argentina}

El botulismo del lactante es una toxi-infección producida por la germinación y toxinogénesis de $C$. botulinum en el intestino del lactante. Las esporas de esta bacteria, ampliamente distribuidas en la naturaleza, son incorporadas por vía digestiva mediante el chupete o cualquier otro objeto contaminado con el suelo, incluyendo las propias manos y, quizás, con menos frecuencia, por la ingestión de ciertos alimentos contaminados con esporas de esta bacteria (miel, jarabe de maíz contaminados o hierbas medicinales contaminadas) ${ }^{14}$.

El primer caso de botulismo infantil fue comunicado en E.U.A. por Arnon, con un total acumulativo de 1.200 casos hasta la actualidad ${ }^{15}$. En Argentina, en 1982 se confirmaron los dos primeros casos de botulismo del lactante en Mendoza ${ }^{16}$ y Buenos Aires ${ }^{17}$.

Al año 2000 se han diagnosticado 275 casos de botulismo infantil en Argentina ${ }^{15}$. La distribución geográfica de los casos según provincia fue: Mendoza 46 (31,7\%), Buenos Aires 45 (31,0\%), Neuquén 16 (11,0\%), San Luis 13 (9,0\%), Río Negro 7 (4,8\%), Chubut 4 (2,8\%), La Pampa 3 (2,1\%) casos, lo mismo que Córdoba y San Juan; Tierra del Fuego, Misiones, Salta, Santa Fe y Tucumán un caso $(0,7 \%)^{18}$. Mendoza es la provincia que más casos de botulismo tiene con respecto a la densidad de población. En todos ellos se trató de neurotoxina tipo A, coherente con el tipo predominante en Argentina. La edad es uno de los rasgos llamativos: oscila entre dos semanas y seis meses, con un promedio de diez semanas. No obstante, se han publicado casos de un paciente de ocho meses y medio y otro de diez días ${ }^{18}$. Cabe destacar que en la provincia de Mendoza, la mayoría de los casos fueron lactantes alimentados a pecho, residentes en medios rurales. Las zonas se caracterizan por precipitación pluvial escasa y frecuentes vientos, factores que facilitan una mayor carga y diseminación de esporas en el ambiente $\mathrm{y}$, en consecuencia, una mayor probabilidad de acceso al tracto digestivo.

Se ha intentado explicar la transmisión del botulismo del lactante por el consumo de alimentos, pero sólo se han identificado esporas en la miel y el jarabe de maíz. En nuestro país, se analizaron 227 muestras de miel, detectándose esporas en ocho de ellas (3,5\%). Otra fuente de botulismo infantil en Argentina son las infusiones caseras. De nueve casos de botulismo infantil ocurridos en San Luis, a siete se les habían suministrado infusiones de hierbas. En un estudio de 100 muestras de plantas medicinales en nuestro país, en cuatro se identificó $C$. botulinum tipo A en poleo, yerba de pollo, anís y sen ${ }^{15}$.

Recientemente, se ha vinculado el botulismo infan- til con el síndrome de muerte súbita. Si bien es improbable que el botulismo infantil sea responsable de una gran proporción de muertes súbitas en lactantes, se estima que entre 3 y 5\% de los niños que mueren con este último diagnóstico son, en realidad, casos de botulismo ${ }^{19}$.

En Chile, el botulismo es una enfermedad de Notificación Obligatoria inmediata según el DS N 158 del MINSAL, cuya confirmación en muestras clínicas y en alimentos, debe hacerse en el Laboratorio de Referencia del Instituto de Salud Pública. La vigilancia de brotes de ETA en Chile no ha reportado casos de esta enfermedad en las últimas décadas; no obstante, sí se han reportado casos muy esporádicos de botulismo infantil asociados al consumo de miel y de infusiones de yerbas silvestres.

\section{Discusión}

En décadas anteriores, condiciones favorables para la supervivencia de las esporas del C. botulinum y su ulterior germinación en los alimentos, eran mucho menos comunes. Sin embargo, métodos perdurables de preparación de ciertas comidas artesanales, nuevas formas de envasado de alimentos comerciales, nuevas preferencias alimenticias o nuevas técnicas para preparar comidas familiares que permiten el crecimiento de C. botulinum, parecen determinar que el botulismo transmitido por alimentos va a continuar afectando a los seres humanos durante un futuro predecible, en los países donde han sido documentados brotes, lo cual no es el caso de Chile, país libre de esta patología ${ }^{1}$.

El botulismo asociado con alimentos nativos de Alaska es casi un problema antiguo, agravado en décadas recientes al alterar prácticas tradicionales en forma insegura, en particular, al incluir el uso de envases de plástico o de vidrio para la fermentación ${ }^{9}$.

Clostridium botulinum raramente causa enfermedad porque las condiciones requeridas para su germinación y la producción de la toxina: $\mathrm{pH}>$ 4,6 (poca acidez), elevada $A_{w}$, ausencia de conservantes, temperatura ambiental y atmósfera anaeróbica, habitualmente no están presentes en los alimentos ${ }^{1}$. Sin embargo, en el período analizado en E.U.A., la ausencia de conservantes, el bajo contenido de sal, alimentos comercialmente producidos y envasados herméticamente sin barreras intrínsecas para la germinación de las esporas de $C$. botulinum se hicieron populares, seguramente, porque fueron percibidos por el público como "más saludables". Sin embargo, un alto contenido de sal no es, por sí solo, preventivo, como lo ejemplifican los brotes asociados a la salsa de porotos 
comercial y a la sopa de almejas. Tampoco colocar la leyenda "Refrigerar" en el envase como barrera para la prevención, asegura cumplimiento ${ }^{2}$.

En varios casos esporádicos de botulismo de origen alimentario no fue posible identificar una fuente alimenticia contaminada. ¿Eran éstos, de hecho, diagnósticos de botulismo de los alimentos? El fracaso para implicar un alimento puede indicar que estos casos fueron mal clasificados. La pesquisa de los brotes tiene algunas limitaciones: la mayor parte de los datos clínicos son recolectados en el momento de la detección de la toxina en el lavado gástrico, en las heces o el alimento; suele no existir registro de notificación o bien, las dificultades para la notificación derivan en información incompleta para una proporción sustancial de casos $^{3}$.

En el brote de botulismo tipo E que afectó 8 de 14 nativos de Alaska que consumieron muktuk, la enfermedad fue rápidamente diagnosticada y tratada. Aunque todas las muestras de muktuk dieron positivas para la toxina tipo E, sólo una de las 13 muestras clínicas de pacientes con botulismo arrojó un resultado positivo en la inoculación intraperitoneal en ratones ${ }^{10}$. Tanto la limitada sensibilidad del ensayo en ratones para la detección de toxina botulínica en muestras clínicas, como se observa en los brotes, así como el hecho de que las pruebas requieren hasta cuatro días para obtener los resultados finales, indican que los médicos no deben esperar la confirmación del laboratorio para hacer el diagnóstico y tomar las decisiones sobre el tratamiento clínico.

Como quedó expresado, ha habido una disminución de la mortalidad por botulismo en Alaska. Esta reducción se debería a varios factores: primero, esfuerzos en salud pública permitieron educar a la población y a los médicos clínicos sobre la prevención, signos, síntomas y la necesidad del tratamiento inmediato del botulismo; segundo, la urgente evacuación de pacientes rurales a modernos hospitales regionales, generalmente en pequeños aviones, es una práctica común; tercero, la antitoxina trivalente del botulismo (anti A, B y E) es almacenada en la mayoría de los hospitales rurales, para que esté siempre disponible para el tratamiento, cuando sea clínicamente indicado ${ }^{9}$.

La toxina tipo E, es responsable de más de $85 \%$ de los casos de botulismo en Alaska, porque muchos de los tradicionales alimentos nativos locales, entre los que se incluyen la cabeza del salmón, la grasa de ballena, la piel y el aceite de foca y los huevos de pescado, son preparados por fermentación bajo condiciones que pueden favorecer la germinación y crecimiento de la neurotoxina tipo E de C. botulinum. Comer grasa de ballena muerta, como se describió en estos brotes, respeta la tradición; sin embargo, alma- cenar la grasa en bolsas plásticas herméticamente selladas que pueden crear un ambiente anaeróbico, es un moderno y peligroso descubrimiento. El uso de envases herméticos para almacenar y fermentar comidas tradicionales se considera que es, al menos en parte, responsable del aumento en la incidencia del botulismo en los alimentos en Alaska desde 1970 hasta la década del $90^{7}$.

Varios estudios antropológicos y paleontológicos han encontrado efectos negativos en la salud, asociados con una rápida transformación cultural y otros estudios han encontrado que los cambios rápidos de dietas de subsistencia a dietas occidentales han sido asociados con aumentos en la incidencia de enfermedad coronaria, obesidad, diabetes mellitus y cáncer entre los nativos de Alaska. Además, el consumir comidas tradicionales puede formar parte de la identidad cultural de grupos que están en transición cultural y, entonces, puede ser perpetuado como una conexión con el pasado. Por ende, se deberían invertir esfuerzos considerables para alentar el consumo de comidas tradicionales entre nativos de Alaska, promoviendo métodos más seguros para almacenar y preparar los alimentos de manera de evitar el botulismo ${ }^{9}$.

Por otra parte, intentar modificar las costumbres alimentarias tradicionales de los nativos por el peligro de contraer botulismo, puede acelerar la pérdida de su identidad cultural y, entonces, eventualmente, disminuir la popularidad de las comidas tradicionales de Alaska, lo cual incidiría negativamente sobre la salud de la población. Una solución lógica al problema del botulismo en el ártico sería dirigir los esfuerzos educacionales en salud pública hacia una comprensión apropiada de los peligros involucrados, lo cual puede hacer mucho para reducirlos al apoyarse en precauciones sanitarias relevantes.

Debido a los numerosos efectos benéficos en la salud -sin mencionar los culturales- del consumo de alimentos tradicionales, sería recomendable que los líderes nativos de Alaska continúen promoviendo el consumo de estos alimentos entre su gente, mientras los educan acerca de los potenciales peligros del almacenamiento y la preparación inapropiada ${ }^{20}$.

En síntesis, para reducir la probabilidad del botulismo de los alimentos, es importante tener en cuenta que el desarrollo y crecimiento de C. botulinum ocurre sólo bajo condiciones particulares que incluyen un medio ambiente anaeróbico, bajo en sales y ácidos, a temperatura ambiente. La prevención puede ser acentuada estableciendo múltiples barreras a la germinación de las esporas, como la acidificación y la reducción de la actividad de agua, en todos los alimentos envasados comercialmente con bajos niveles de oxígeno ${ }^{21}$. Se previene la germinación de las esporas con bajo $\mathrm{pH}$ 
$(<4,5)$, refrigeración $\left(<4{ }^{\circ} \mathrm{C}\right)$, baja actividad del agua (Aw $=0,93$ o menor) y atmósfera aeróbica. Las esporas se destruyen por calentamiento a $120{ }^{\circ} \mathrm{C}$ durante 30 minutos en autoclave, mientras que las toxinas se inactivan a temperaturas de $80{ }^{\circ} \mathrm{C}$ durante 20 minutos o $90{ }^{\circ} \mathrm{C}$ por 10 minutos $^{3}$. Definitivamente, el consumidor, el manipulador o vendedor de alimentos, puede controlar el crecimiento de los patógenos, limitando una o más de las condiciones necesarias para el crecimiento de C. botulinum.

\section{Resumen}

La causa más frecuente de botulismo de los alimentos es la elaboración y consumo de conservas caseras, que son procesadas de manera inapropiada, creando un ambiente anaeróbico que favorece la supervivencia de las esporas, su germinación, reproducción y síntesis de toxina. Entre 1992 y 2003, se han notificado en Argentina 34 casos de botulismo transmitido por alimentos y 275 casos de botulismo infantil. La gravedad de los síntomas depende de la ingesta de esporas viables por el paciente. Formas leves de botulismo pueden no requerir asistencia médica en absoluto, por lo que si un paciente presenta sólo náuseas y ligeros síntomas neurológicos, existe la posibilidad de que un caso de botulismo pueda no ser diagnosticado. En Argentina, la mayoría de los casos de botulismo se relacionan con alimentos de preparación casera. Es importante para la prevención, educar a los consumidores, desincentivando la ingesta de este tipo de alimentos.

\section{Referencias}

1.- Dobbs K L, Austin J W. Clostridium botulinum. In: Doyle MP, Beuchat LR, Montville TJ, editors. Food Microbiology: Fundamentals and Frontiers. Washington: ASM Press; 1997. p. 288-304.

2.- Cherington M. Clinical spectrum of botulism. Muscle Nerve 1998; 21: 701-10.

3.- Peck M W. Clostridia and foodborne disease. Microbiol Today 2002; 29: 9-12.

4.- Sobel J, Tucker N, Sulka A, McLaughlin J, Maslanka S. Foodborne botulism in the United States, 1990-2000. Emerg Infect Dis 2004; 10: 1606-11.

5.- Varma J K, Katsitadze G, Moiscrafishvili M, Zardiashvili T, Chokheli M, Tarkhashvili N, et al. Signs and symptoms predictive of death in patients with foodborne botulism. Republic of Georgia, 1980-2002. Clin Infect Dis 2004; 39: 357-62.

6.- Arnon $\mathrm{S}$, Schechter R, Inglesby $\mathrm{T} \mathrm{V}$, Henderson D A, Bartlett JG, Ascher M S, et al. Botulism toxin as a biological weapon: medical and public health management. JAMA 2001; 285: 1059-70.

7.- Chiou L A, Hennessy T W, Horn A, Carter G, Butler J C. Botulism among Alaska natives in the Bristol Bay area of southwest Alaska: a survey of knowledge, attitudes, and practices related to fermented foods known to cause botulism. Int J Circumpolar Health 2002; 61: 50-60.

8.- Eisenberg M S, Bender T R. Botulism in Alaska, 1947 through 1974: Early detection of cases and investigation of outbreaks as a means of reducing mortality. JAMA 1976; 235: 35-8.

9.- Shaffer N, Wainwright R B, Middaugh J P. Botulism among Alaska natives: the role of changing food preparation and consumption practices. West J Med 1990; 153: 390-3.

10.- McLaughlin J B, Sobel J, Lynn T, Funk E, Middaugh J P. Botulism type E outbreak associated with eating a beached whale, Alaska. Emerg Infect Dis 2004; 10: 1685-7.

11.- Bianchini H M. Update on Pan-American research on anaerobes: The situation in Argentina. Clin Infect Dis 1997; 25 (Suppl 2): S244-5.

12.- Cusmano L, Romano M, Bucci Z. Análisis epidemiológico del botulismo del adulto. Doce años de experiencia en un centro especializado. El Muñiz hoy 2004; 7: 65-7.

13.- Villar R, Shapiro R, Busto S, Riva-Posse C, Verdejo G, Farace M, et al. Outbreak of type A botulism and development of a botulism surveillance and antitoxin release system in Argentina. JAMA 1999; 281: 1334-40.

14.- Shapiro R L, Hatheway C, Becher J, Swerdlow D L. Botulism surveillance and emergency response: a public health strategy for global challenge. JAMA 1997; 278: 433-5.

15.- Jong L I, Fernández R A, Bianco M I, Ciccarelli AS. Transmisión del botulismo del lactante. Pren Med Argent 2003; 90: 188-94.

16.- Lentini C, Fernández R A, Cicarelli A S, Giménez D F. Botulismo del lactante. ¿Una nueva enfermedad? Arch Argent Pediatr 1984; 82: 197-8.

17- Gianantonio C, Domínguez M E, Esteban N, Schnitzler E J. Botulismo del lactante. Arch Argent Pediatr 1984; 82: 193-6.

18.- Fernández R A, Ciccarelli A S, de Centorbi O N P, Centorbi H, Rosetti F A, de Jong L, et al. Infant botulism in Argentina, 1982-1997. Anaerobe 1999; 5: $177-9$.

19.- Justo L, Mozzi M. Botulismo del lactante: Forma clínica leve. Medicina Infantil. Rev Hosp Nac Pediatr J Garrahan 1996; 3: 49-51.

20.- Wainwright R B, Heyward W L, Middaugh J P, Hatheway C L, Harpster A P, Bender T R. Food-borne botulism in Alaska, 1947-1985: epidemiology and clinical findings. J Infect Dis 1988; 157: 1158-62.

21.- Galazka A, Przybylska A. Surveillance of foodborne botulism in Poland, 1960-1998. Euro Surveill 1999; 4: 69-72. 